\title{
Left upper division segmentectomy with a simultaneous displaced bronchus and pulmonary arteriovenous anomalies: a case report
}

\author{
Kazuki Hayashi ${ }^{1 *}$, Makoto Motoishi ${ }^{2}$, Kanna Horimoto ${ }^{3}$, Satoru Sawai ${ }^{3}$ and Jun Hanaoka ${ }^{1}$
}

\begin{abstract}
Background: A displaced bronchus is a rare disorder of the left upper lobe. Displaced bronchi are often accompanied by an anomaly of a pulmonary artery, but rarely of a pulmonary vein.

Case presentation: We here present a patient with primary lung cancer and simultaneous migration abnormalities of the pulmonary artery and vein in a displaced bronchus of the left upper lobe. Previous reports and our findings indicate that anomalies of the pulmonary artery and vein combined with a displaced bronchus of the left upper lobe have the following characteristics: (1) the left main pulmonary artery does not cross the dorsal side of the displaced bronchus; (2) $V^{1+2}$ returns to the inferior pulmonary vein; and (3) there is an accessory fissure (aberrant fissure) in the segments dominated by the displaced bronchus.

Conclusions: Prevention of intraoperative damage during procedures for a displaced bronchus and pulmonary arteriovenous anomalies requires careful preoperative evaluation and surgical technique with particular attention to the above-listed characteristics.
\end{abstract}

Keywords: Lung cancer, Displaced bronchus, Pulmonary artery anomaly, Pulmonary venous anomaly, Accessory fissure

\section{Background}

Many bronchial bifurcation abnormalities have been reported in the right upper lobe [1-3]; however, such abnormalities are rare in the left upper lobe. A displaced bronchus is frequently accompanied by the pulmonary artery taking an abnormal course [4-15], but few patients in whom the pulmonary vein also takes an abnormal course have been reported. We here report performing a segmentectomy for a left upper lobe lung cancer in a patient with a displaced bronchus in whom the left main pulmonary artery and superior pulmonary vein both took abnormal courses.

\footnotetext{
* Correspondence: hayashik@belle.shiga-med.ac.jp

${ }^{1}$ Division of General Thoracic Surgery, Department of Surgery, Shiga University of Medical Science, Setatsukinowa-cho, Otsu, Shiga 520-2192, Japan

Full list of author information is available at the end of the article
}

\section{Case presentation}

A 78-year-old man was referred to our department for suspected left upper lobe lung cancer (cT1cNOM0 stage IA3). He had a history of percutaneous coronary intervention for angina pectoris, and internal carotid artery stenosis and hypertension for which he was receiving medical treatment. He had been a heavy smoker. The Brinkman Index was 1000 . On chest auscultation, fine crackles were heard on the back bilaterally. Blood tests showed no abnormal findings other than a high carcinoembryonic antigen concentration $(7.2 \mathrm{ng} / \mathrm{mL})$. Pulmonary function tests showed an obstructive disorder as evidenced by a forced expiratory volume 1.0\% (FEV 1.0\%) (G) of 68.8\%.

A chest radiograph and chest computed tomography (CT) showed a tumor of maximum diameter $30 \mathrm{~mm}$ in the left lung $\mathrm{S}^{1+2}$ segment (Fig. 1a, b), emphysema of the upper lobe, and fibrosis of the left lower lobe. The patient was diagnosed as having combined pulmonary fibrosis and emphysema (Fig. 1c). Additionally, an

(C) The Author(s). 2018 Open Access This article is distributed under the terms of the Creative Commons Attribution 4.0 International License (http://creativecommons.org/licenses/by/4.0/), which permits unrestricted use, distribution, and 


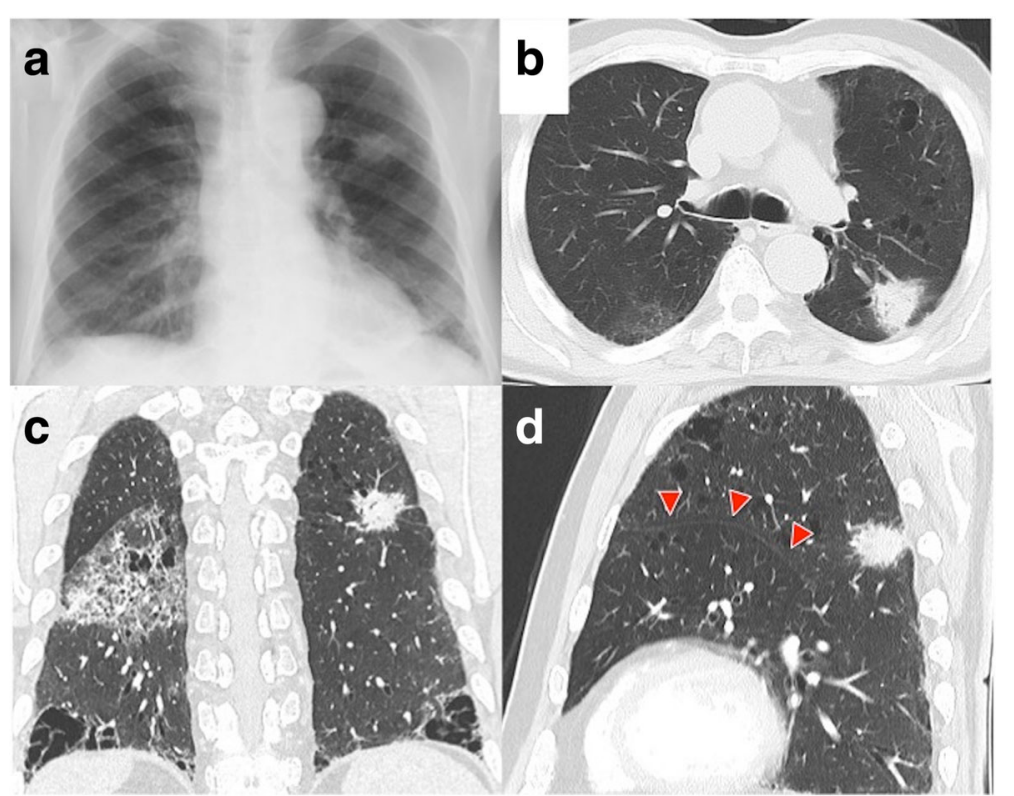

Fig. 1 a, b Chest radiograph and CT image showing a mass in the left lung $S^{1+2}$ segment. c Chest CT image showing a mass, emphysema in the upper lobes, and fibrosis in the lower lobes. $\mathbf{d}$ Chest $C T$ image showing an accessory fissure between $S^{1-3}$ and $S^{4+5}$ (arrowheads)

accessory fissure (aberrant fissure) was identified between the $S^{1-3}$ and $S^{4+5}$ segments (Fig. 1d). Bronchoscopy had been performed at the referring institution and was not repeated in our department. Bronchoscopic images were not viewed preoperatively and no bronchial abnormalities were mentioned in the report of the referring institution's bronchoscopy. No histological diagnosis had been obtained by bronchoscopy.

In consideration of the patient's age, his combined pulmonary fibrosis and emphysema, and the presence of an accessory fissure between $\mathrm{S}^{1-3}$ and $\mathrm{S}^{4+5}$, left upper division segmentectomy by video-assisted thoracoscopic surgery was selected as the procedure of choice. $\mathrm{V}^{1-3}$ was identified on the ventral side of the mediastinum and dissected (Fig. 2a). The branches of $\mathrm{A}^{3}, \mathrm{~A}^{1+2}$ a, $\mathrm{A}^{1+}$ ${ }^{2}+\mathrm{c}$ were identified and divided (Fig. 2b) by reaching the pulmonary arterial wall from the accessory fissure of $\mathrm{S}^{1-3}$ and $\mathrm{S}^{4+5}$. Subsequently, the IPV and $\mathrm{V}^{1+2}$, which joined the IPV, were identified on the dorsal side of the mediastinum, and $\mathrm{V}^{1+2}$ b was divided (Fig. 2c). $\mathrm{B}^{1+2}+\mathrm{B}^{3}$, which were on the dorsal side of the left main pulmonary artery, were identified and divided (Fig. 2d). Incomplete lobulation was noted dorsally between the upper and lower lobes. Therefore, to secure sufficient tumor margins, part of $S^{6}$ was included in the upper lobe and the incomplete lobulation was divided with a stapler. $\mathrm{S}^{1-3}$ was then excised (Fig. 2e). The operation time was $4 \mathrm{~h}$ and $49 \mathrm{~min}$ and amount of bleeding was $30 \mathrm{~mL}$.

Three-dimensional reconstructed images of the pulmonary artery and vein had been prepared preoperatively, whereas images that also included the bronchi were only prepared postoperatively. The latter showed the following: $\mathrm{B}^{1+2}+\mathrm{B}^{3}$ was branching from the left main bronchus, followed by a bronchus that corresponded to the middle bronchial trunk of the right lung, and $\mathrm{B}^{4+5}$ and the lower lobe bronchus (Fig. 3a, b); the left main pulmonary artery was on the ventral side of $\mathrm{B}^{1+2}+\mathrm{B}^{3}$ and did not cross the dorsal side of the left main bronchus; and $\mathrm{V}^{1+2}{ }_{\mathrm{b}}$ joined the inferior pulmonary vein (IPV) on the dorsal side of the pulmonary artery (Fig. 3a). In addition, when the image of the sagittal section was reviewed again postoperatively, the above listed features were visible on plain CT (Fig. 3c).

Additionally, postoperative review of available bronchoscopic images revealed an abnormal bronchial course (Fig. 4).

Pathological examination of the resected specimen resulted in a diagnosis of adenocarcinoma with metastases in the mediastinal lymph nodes and of pathological stage pT1cN2M0 stage IIIA. The postoperative course was uneventful and the patient was discharged on postoperative day 8. No recurrence had occurred by 1 year after surgery.

\section{Discussion}

A displaced bronchus is defined as one that branches away from its customary position [16]. The prevalence of this anomaly is only 0.64 and $75 \%$ are in the right upper lobe [17]. A displaced bronchus in the left upper lobe is rare, and one with pulmonary arterial 


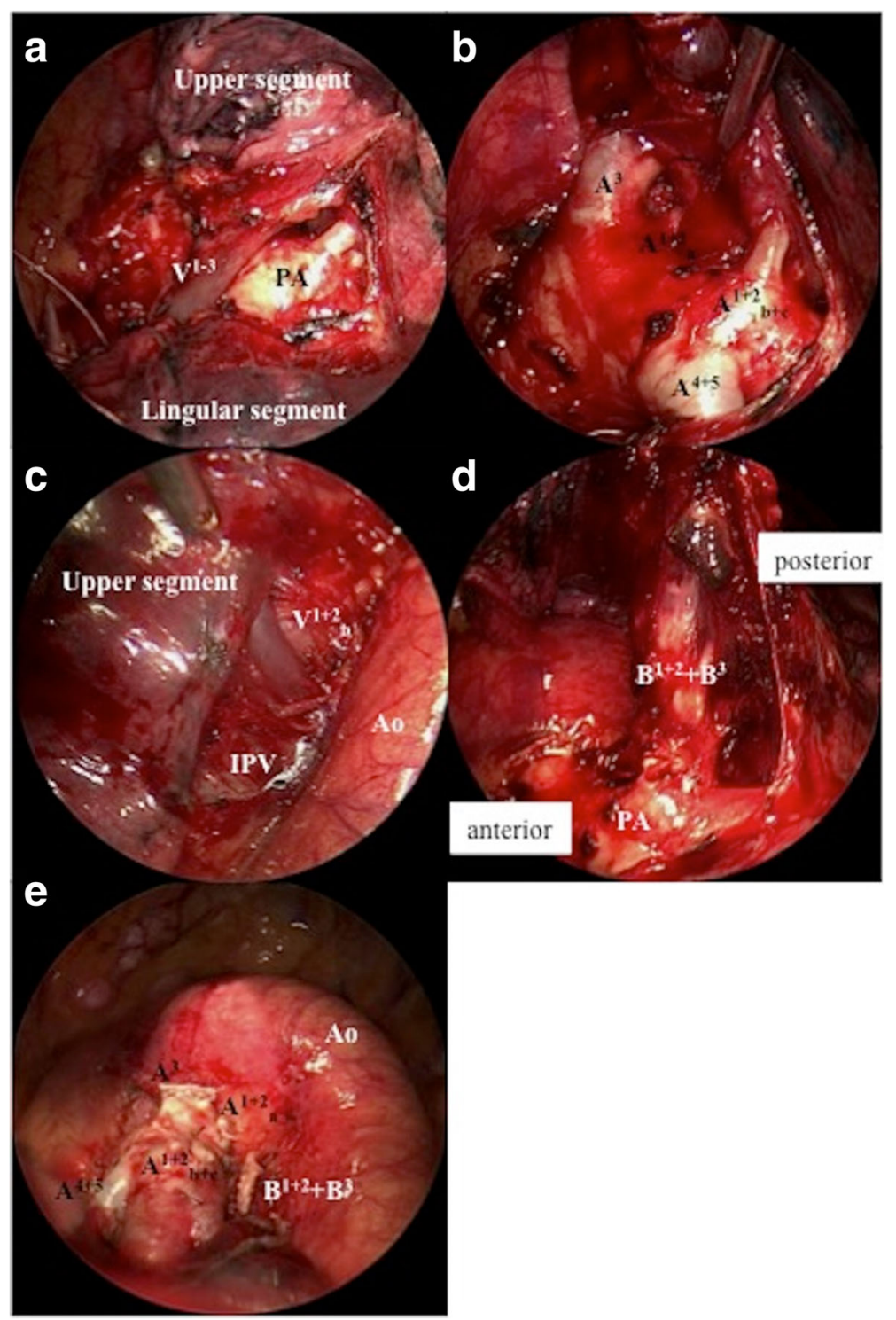

Fig. 2 a Intraoperative image showing $V^{1-3}$ on the ventral side of the mediastinum. $\mathbf{b}$ Intraoperative image showing the branches of $A 3, A^{1+2}$ a $A^{1+2} b+c$ and $A^{4+5}$. $c$ Intraoperative image showing $V^{1+2}$ joining the IPV. (D) Intraoperative image showing $B^{1+2}+B^{3}$ on the dorsal side of the left main pulmonary artery. e Intraoperative image after left upper division segmentectomy. IPV, inferior pulmonary vein

and venous abnormalities even rarer. To the best of our knowledge, 15 surgical cases of a displaced bronchus in the left upper lobe have been reported, including the present one $[4-16,18,19]$. Of these, only four patients, including our patient, had pulmonary arterial and venous malformations (Table 1). About $75 \%$ of pulmonary veins with an abnormal course involve $\mathrm{V}^{1}+2$. Features that are common to anomalies of the pulmonary artery and vein combined with a displaced bronchus of the left upper lobe are as follows: (1) the left main pulmonary artery does not cross the dorsal side of the displaced bronchus; (2)
$\mathrm{V}^{1+2}$ returns to the inferior pulmonary vein; and (3) there is an accessory fissure in the segments dominated by the displaced bronchus.

Surgeons need to pay attention to these features when performing preoperative evaluation and surgery. In our case, that the pulmonary vein had an abnormal course was identified by preoperative $\mathrm{CT}$, whereas the abnormal courses of the bronchus and pulmonary artery were first recognized intraoperatively. Preoperative images should be carefully evaluated; however, details of any abnormal anatomy may be difficult to identify or assess on axial images. Additionally, three-dimensional reconstructed 


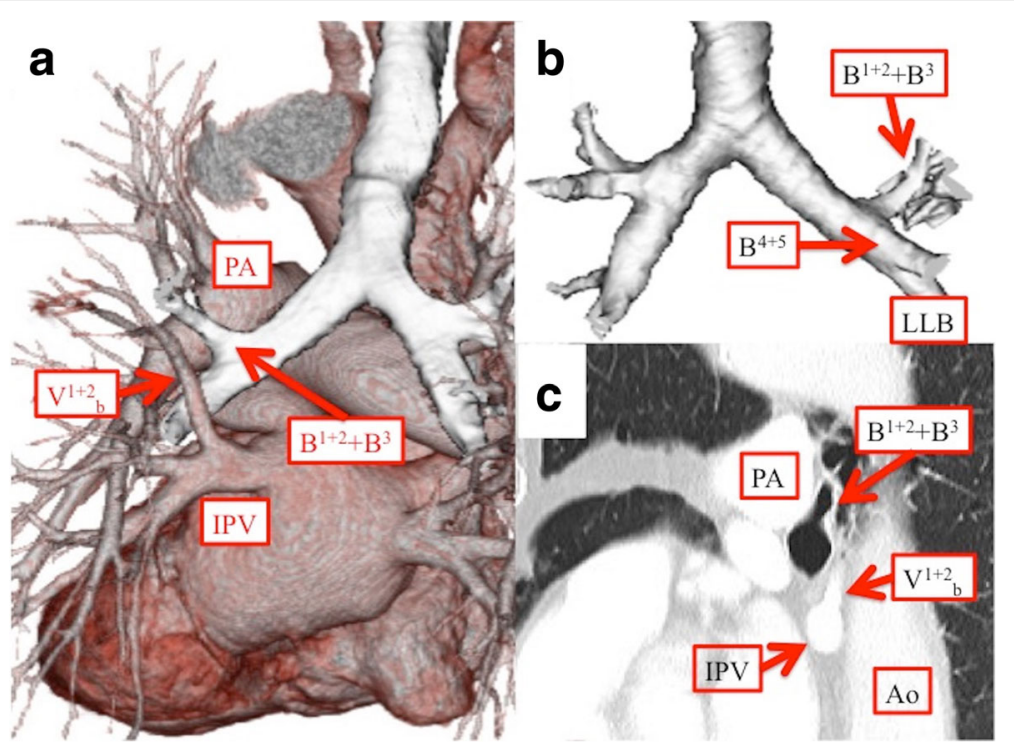

Fig. 3 a, c Three-dimensional reconstructed image and chest CT image (sagittal) showing that the left main pulmonary artery is on the ventral side of $B^{1+2}+B^{3}$ and does not cross the dorsal side of the left main bronchus and that $V^{1+2}$ joins the IPV on the dorsal side of the pulmonary artery. $\mathbf{b}$ Three-dimensional reconstructed image showing that $B^{1+2}+B^{3}$ branches from the left main bronchus, followed by $B^{4+5}$ and the lower lobe bronchus. Ao, aorta; IPV, inferior pulmonary vein; LLB, left lower bronchus; PA, pulmonary artery

images including the bronchi are not always prepared preoperatively. Therefore, how to adequately evaluate a surgical candidate preoperatively without missing important features is an issue that needs to be addressed. One means of addressing this issue could be to focus on accessory fissures. Because accessory fissures are the most easily detected of the above-mentioned abnormalities, whenever an accessory fissure is recognized the surgeon must investigate the possibility of blood vessels or bronchi having abnormal courses. An accessory fissure and abnormal courses of bronchi and blood vessels are often present simultaneously [20]; the reason for this association is unclear.

Nine of the 15 reported patients with a displaced bronchus in the left upper lobe had accompanying incomplete lobulation between the upper and lower lobes $[4,5,7-9,11,12,18]$. There is a tendency for incomplete lobulation between the upper and lower lobe when there is an accessory fissure in the upper lobe. In such cases, this incomplete lobulation needs to be divided during lung resection. However, in some previously reported patients, the abnormal courses of blood vessels and the bronchus had not been detected preoperatively; thus, some of them were damaged during division of incomplete lobulation $[6,8]$. In particular, with a pulmonary venous anomaly such as our patient had, $\mathrm{V}^{1+2}$ lies to the dorsal side of the mediastinum, making it highly likely that it will be damaged when dividing incomplete lobulation. The no-touch fissure technique is useful for preventing intraoperative damage when performing lobectomy or segmentectomy in a patient with a displaced bronchus, [11]. This technique requires dividing of the pulmonary artery and bronchus before dividing incomplete lobulation. However, even when using a technique that involves dividing blood vessels and bronchi first, there is still a danger of intraoperative damage if the

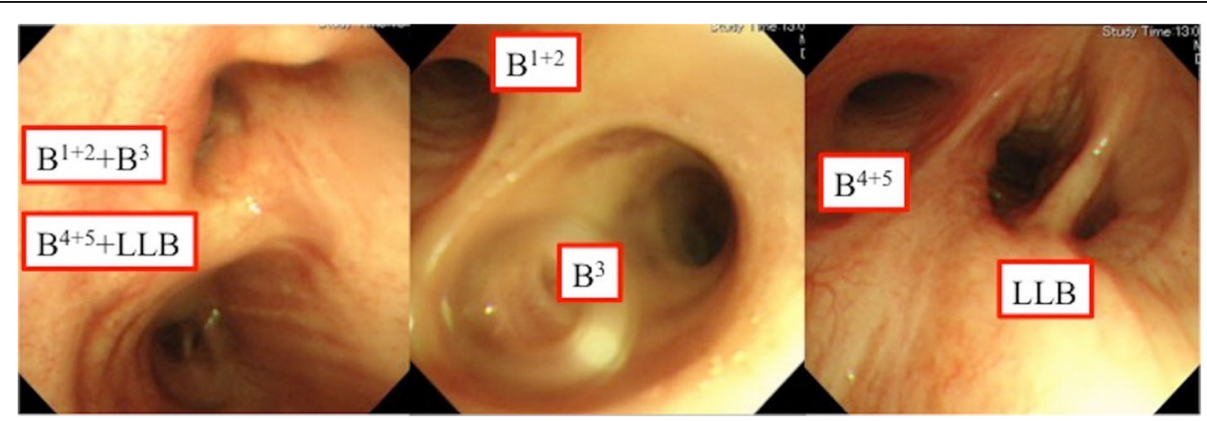

Fig. 4 Bronchoscopy showing $B^{1+2}+B^{3}$ branches from the left main bronchus, followed by $B^{4+5}$ and the lower lobe bronchus 
Table 1 Previous reports of lung resection in patients with a displaced bronchus of the left upper lobe

\begin{tabular}{|c|c|c|c|c|c|c|c|c|}
\hline First author & Year & Age $(y) /$ sex & Diagnosis & $\begin{array}{l}\text { Displaced } \\
\text { bronchus }\end{array}$ & $\begin{array}{l}\text { Position of displaced } \\
\text { bronchus }\end{array}$ & Lobulation & Procedure & Anomalous PV \\
\hline Anno & 1959 & $28 / \mathrm{M}$ & Tuberculosis & $\mathrm{B}^{1+2}+\mathrm{B}^{3} / \mathrm{B}^{4+5}$ & Behind the MPA & $S^{4+5} / S^{1+2+6-10}$ & $\mathrm{~S}^{1-3}$ Seg. & $V^{1+2}$ \\
\hline Takahashi & 1992 & $47 / F$ & $\begin{array}{l}\text { Sclerosing } \\
\text { hemangioma }\end{array}$ & $B^{1+2} / B^{3}+B^{4+5}$ & N.D. & $S^{3-5} / S^{1+2+6-10}$ & $S^{3-5}$ Seg. & N.D. \\
\hline Motohashi & 1995 & $52 / F$ & Lung cancer & $\begin{array}{l}B^{1+2}{ }^{4} / B^{1+2} b, c+B^{3} / \\
B^{4+5}\end{array}$ & N.D. & N.D. & Pneumonectomy & None \\
\hline Okamoto & 1999 & $59 / \mathrm{M}$ & Lung cancer & $B^{1+2}+B^{3} / B^{4+5}$ & Behind the MPA & $S^{1-3} / S^{4-10}$ & LLL & None \\
\hline Shimamoto & 2008 & $81 / F$ & Lung cancer & $B^{1+2} / B^{3}+B^{4+5}$ & Behind the MPA & $S^{1-5} / S^{6-10}$ & $S^{1+2}$ Seg. & N.D. \\
\hline Tarukawa & 2010 & $65 / M$ & Lung cancer & $B^{1+2}+B^{3} / B^{4+5}$ & Behind the MPA & $S^{1-3} / S^{4-10}$ & $S^{1-3}$ Seg. & N.D. \\
\hline Tsukioka & 2011 & $62 / F$ & Lung cancer & $B^{1+2} / B^{3}+B^{4+5}$ & Behind the MPA & $S^{1-2} / S^{3-10}$ & LUL & N.D. \\
\hline Ikuta & 2013 & $83 / \mathrm{M}$ & Lung cancer & $B^{1+2} / B^{3}+B^{4+5}$ & Behind the MPA & $S^{1-2} / S^{3-10}$ & LUL & $V^{1+2}$ \\
\hline Katayama & 2013 & $55 / \mathrm{M}$ & Lung cancer & $B^{1+2}+B^{3} / B^{4+5}$ & Behind the MPA & $S^{1-3} / S^{4+5} / S^{6-10}$ & $S^{1-3}$ Seg. & N.D. \\
\hline Asakura & 2014 & $52 / \mathrm{M}$ & Lung cancer & $B^{1+2} / B^{3}+B^{4+5}$ & Behind the MPA & $S^{1-2} / S^{3-10}$ & LUL & N.D. \\
\hline Kawano & 2014 & $59 / M$ & Lung cancer & $B^{1+2}+B^{3} / B^{4+5}$ & Behind the MPA & $S^{1-3} / S^{4-10}$ & $S^{1-3}$ Seg. & None \\
\hline Yaginuma & 2015 & $63 / F$ & Lung cancer & $B^{1+2}+B^{3} / B^{4+5}$ & Behind the MPA & $S^{1-3} / S^{4+5} / S^{6-10}$ & $S^{1-3}$ Seg. & N.D. \\
\hline Chiba & 2015 & $57 / M$ & Lung cancer & $B^{1+2}+B^{3} / B^{4}+5$ & Behind the MPA & $S^{1-3} / S^{4+5} / S^{6-10}$ & $\mathrm{~S}^{1-3}$ Seg. & $\begin{array}{l}\text { Common duct of } \\
\text { the SPV and IPV }\end{array}$ \\
\hline Onuki & 2016 & $83 / F$ & Lung cancer & $B^{1+2} / B^{3}+B^{4+5}$ & Behind the MPA & $\begin{array}{l}S^{1+2} / S^{3} / S^{4+5} / \\
S^{6-10}\end{array}$ & LUL & None \\
\hline $\begin{array}{l}\text { Present } \\
\text { case }\end{array}$ & 2016 & $78 / \mathrm{M}$ & Lung cancer & $B^{1+2}+B^{3} / B^{4+5}$ & Behind the MPA & $S^{1-3+6} / S^{4+5} / S^{8-10}$ & $S^{1-3}$ Seg. & $V^{1+2}$ \\
\hline
\end{tabular}

$M$ male, $F$ female, N.D. not described, LUB left upper lobe bronchus, MPA main pulmonary artery, Seg. segmentectomy, LLL left lower lobectomy, LUL left upper lobectomy, SPV superior pulmonary vein, IPV inferior pulmonary vein

surgeon has insufficient information concerning the course of blood vessels and bronchi. Patients with anomalies similar to those of our patient tend to have an accessory fissure. In such cases, approaching the pulmonary artery from the accessory fissure and deliberately detaching the blood vessels and bronchus are essential for preventing intraoperative damage.

\section{Conclusions}

When the bronchi and pulmonary artery and veins all take abnormal courses in the left lung, the following is usually present. (1) The left main pulmonary artery does not cross the dorsal side of the displaced bronchus. (2) $\mathrm{V}^{1+2}$ returns to the inferior pulmonary vein. (3) There is an accessory fissure in the segments dominated by the displaced bronchus. Surgeons need to be aware of these features to prevent damage during surgery. In particular, focusing on any accessory fissure when performing preoperative evaluations may maximize detection of associated anomalies.

\section{Abbreviations}

Ao: Aorta; CT: Computed tomography; FEV 1.0\%: Forced expiratory volume 1.0\%; IPV: Inferior pulmonary vein; LLB: Left lower bronchus; LLL: Left lower lobectomy; LUB: Left upper lobe bronchus; LUL: Left upper lobectomy; MPA: Main pulmonary artery; N.D.: Not described; PA: Pulmonary artery; Seg.: Segmentectomy; SPV: Superior pulmonary vein

\section{Acknowledgments}

We thank Ellen Knapp, PhD, and Trish Reynolds, MBBS, FRACP, from Edanz Group (www.edanzediting.com/ac) for editing a draft of this manuscript.

\section{Availability of data and materials}

All data generated or analyzed during this study are included in this published article.

\section{Authors' contributions}

$\mathrm{KH}, \mathrm{MM}$, and SS carried out the operation and postoperative care of the patient. KH was a major contributor in writing the manuscript. All other authors contributed to data collection and interpretation, and critically reviewed the manuscript. All authors read and approved the final manuscript.

\section{Ethics approval and consent to participate}

This case report was approved by the local institutional and ethics review board. Because it was not a trial, consent to participate was not required.

\section{Consent for publication}

Appropriate written informed consent was obtained for the publication of this case report and accompanying images.

\section{Competing interests}

The authors declare that they have no competing interests.

\section{Publisher's Note}

Springer Nature remains neutral with regard to jurisdictional claims in published maps and institutional affiliations.

\section{Author details}

'Division of General Thoracic Surgery, Department of Surgery, Shiga University of Medical Science, Setatsukinowa-cho, Otsu, Shiga 520-2192, Japan. ${ }^{2}$ Department of Thoracic Surgery, Mitsubishikyoto Hospital, 1 Katsuragosyo-cho, Nishikyo-ku, Kyoto 615-8087, Japan. ${ }^{3}$ Department of 
Thoracic Surgery, National Hospital Organization Kyoto Medical Center,

Fukakusamukaihata-cho, Fushimi-ku, Kyoto 612-8555, Japan.

Received: 26 February 2018 Accepted: 10 May 2018

Published online: 16 May 2018

\section{References}

1. Tanida N, Uyama T, Takahashi K, Sumitomo M, Monden Y. Two cases of lung cancer arising in lungs with anomalous bronchi. J Jpn Soc Resp Endoscopy. 1993;15:89-94.

2. Sakaguchi $\mathrm{K}$, Horio H. Lung cancer in the right upper lobe with displaced anomalous bronchi: a report of two cases. J Jpn Soc Resp Endoscopy. 2013;35: 666-70.

3. Tajima K, Uchida N, Sasamoto H, Okada T, Kohri T, Mogi A, et al. Lung adenocarcinoma with anomalous bronchi and pulmonary veins preoperatively identified by computed tomography. Thorac Cancer. 2016;7: 599-601.

4. Anno H, Takase A, Suzuki A, Kinoshita I. Bifurcation anomaly of the bronchial branch and pulmonary blood vessel in the left upper lobe [translated from Japanese]. Jpn J Clin Radiol. 1959:4:480-92.

5. Okamoto T, Okubo K, Kato T, Kurahashi Y, Isobe J, Ueno Y, et al. A case of resection of lung cancer with displaced anomalous lingular bronchus. J Jpn Soc Resp Endoscopy. 1999;21:414-7

6. Shikamoto A, Takao M, Kodama H, Murashima S, Shomura S, Tarukawa T, et al. A case of left apicoposterio segmentectomy for lung cancer occurring in a displaced anomalous bronchus. J Jpn Soc Resp Endoscopy. 2008;30:210-4.

7. Tarukawa T, Kaneda M, Adachi K. A resected case of large cell neuroendocrine carcinoma of the lung with a displaced anomalous bronchus. Jpn J Chest Surg. 2010;24:1086-91.

8. Tsukioka T, Yamamoto R, Takahama M, Nakajima R, Tada H. A case of lung cancer arising from abnormal bronchi. J Japan Assoc Chest Surg. 2011;25(4):460.

9. Ikuta Y, Tamura K, Sakamoto A, Hidaka K. Lung cancer in the left upper lobe with a displaced anomalous left B1+2 bronchus accompanied by an anomalous V1+2 pulmonary vein: a surgical case. Jpn J Chest Surg. 2013;27: 729-33.

10. Katayama Y, Kusagawa H, Komada T, Shomura S, Ozu Y. Lung cancer occurring in a left upper division which is mirror imaged to a right upper lobe. J Thorac Surg. 2013:66:227-9.

11. Asakura K, Imanishi N, Matsuoka T, Nagai S, Matsuoka K, Ueda M, et al. Video-assisted thoracic surgery lobectomy for lung cancer with displaced B1+2. Ann Thorac Cardiovasc Surg. 2014;20:486-9.

12. Kawano D. A case of resection of lung cancer accompanied by displaced anomalous right upper bronchus, lingular bronchus, and pulmonary artery. Jpn J Chest Surg. 2014;28:505-8.

13. Yaginuma $H$, Fuiii $K$, Miyamoto $H$. A resected case of lung cancer with a displaced anomalous bronchus. Jpn J Chest Surg. 2015;29:684-8.

14. Chiba N, Tomioka Y, Toyazaki T, Ueda Y, Gotoh M, Nakagawa T. Two cases of pulmonary segmentectomy for lung cancer with distinct aberrant division between the left upper and lingular segments. Jpn J Chest Surg. 2016;30:834-9.

15. Onuki T, Ueda S, Yamaoka M, Inagaki MA. Case of left upper lung cancer diagnosed as a left $\mathrm{B}^{1+2}$ displaced bronchus during video-assisted thoracoscopic surgery [translated from Japanese]. J Thorac Surg. 2016;69:517-20.

16. Foster-Carter AF. Broncho-pulmonary abnormalities. Br J Tuberc Dis Chest. 1946:40:111-24.

17. Ohta S, Saito Y, Usuda K, Kanma K, Sagawa M, Sato M, et al. Tracheobronchial anomalies: report of 71 cases. J Jpn Soc Resp Endoscopy. 1986:8:122-30

18. Takahashi K, Masuda S, Uekusa T, Nukiwa T, Kira S. An operated case with sclerosing hemangioma located in a supernumerary lobe containing an anomalous bronchus. Jpn J Lung Cancer. 1992;32:565-70.

19. Motohashi S, Yamaguchi Y, Takeda T, Aoyagi H, Ohtsuka T, Yokosuka T, et al. A case of lung squamous cell carcinoma in anomalously situated subsegmental bronchus of left upper lobe; a case report. Jpn J Chest Surg. 1995;9:181-6.

20. Mawatari T, Koshino T, Morishita K, Watanabe A, Ichimiya Y, Abe T, et al. Pitfall in pulmonary lobectomy or segmentectomy when aberrant Iobulation occurs: an anatomical study. Jpn J Chest Surg. 2000;14:591-601.

\section{Ready to submit your research? Choose BMC and benefit from:}

- fast, convenient online submission

- thorough peer review by experienced researchers in your field

- rapid publication on acceptance

- support for research data, including large and complex data types

- gold Open Access which fosters wider collaboration and increased citations

- maximum visibility for your research: over $100 \mathrm{M}$ website views per year

At BMC, research is always in progress.

Learn more biomedcentral.com/submissions 